\title{
A 4-year-old with a non-tender dorsal phalangeal lump: diagnosis and discussion
}

\author{
Leon Mieczyslaw $\operatorname{Sergot}^{1} \cdot$ Savvas Andronikou ${ }^{2,3} \cdot$ Simon Thomas $^{3}$
}

Published online: 2 November 2017

(C) ISS 2017

Keywords Pediatric $\cdot$ Radiology $\cdot$ Nora lesion $\cdot$ BPOP

\section{Diagnosis}

Bizarre parosteal osteochondromatous proliferation (BPOP).

\section{Discussion}

Bizarre parosteal osteochondromatous proliferation (also known as Nora's lesion) was first described by Nora et al. in 1983 [1]. It is a rare exophytic osteochondral lesion that typically affects the hands or feet, with cases also documented in the skull and long bones. A recent case report from 2014 stated that there had only been 200 published cases up to that point [2]. We performed a subsequent literature search, which only yielded a further 13 cases published to date. It is a particularly rare occurrence in children, with most phalangeal lesions being described in the adult population in the third and fourth decades.

The case presentation can be found at https://doi.org/10.1007/s00256017-2804-5

Leon Mieczyslaw Sergot

leon.sergot@doctors.org.uk

1 University Hospitals Bristol NHS Trust, Marlborough Street, Bristol BS1 3NU, England

2 Department of Paediatric Radiology, University of Bristol, Bristol, England

3 Bristol Royal Hospital for Children, Bristol, England
A benign lesion, the main differentials include osteochondroma, parosteal osteosarcoma, and chondrosarcoma. Although ultimately a histological diagnosis, there are radiological features that distinguish it from its main differential, the osteochondroma. Both have a cartilaginous cap; however, BPOP demonstrates more irregular matrix calcification and unlike osteochondromata, there is no communication with the medullary canal [3]. Osteochondromata also typically orientate away from the physis, which is not a defining characteristic of BPOP.

A further differential includes turret exostosis, otherwise known as an acquired osteochondroma. Predominantly affecting the middle and proximal phalanges of the hand, turret exostoses are usually secondary to minor injury, resulting in the formation of a subperiosteal haematoma that subsequently ossifies $[4,5]$. Radiologically very similar to BPOP, both have been described as belonging to the same lesional spectrum [6]. However, turret exostoses are characterised by pain and softtissue swelling, as opposed to the non-tender and nontraumatic characteristics of the BPOP in this case.

The initial radiograph at presentation demonstrated a broad-based cortical exophytic lesion arising from the diametaphysis of the middle phalanx of the right ring finger. There was no periosteal reaction or soft-tissue component (Fig. 1).

On subsequent follow-up imaging 3 months later, the lesion had continued to grow, but failed to demonstrate any aggressive features (Fig. 2a and b). BPOP was considered the most likely diagnosis with a plan made for confirmation by excisional biopsy. Excision is recommended in symptomatic cases of BPOP [6], and in this case, the patient had lost volar flexion at the distal interphalangeal joint because of the mass effect of the lesion on the adjacent tendons. However, BPOP lesions should be allowed to mature before excision, due to the otherwise high rates of recurrence [7]. Before 
excisional biopsy, and following the advice of the local Tumour Board, a CT was performed for pre-operative planning to demonstrate a zone of cleavage around the central extensor slip (Fig. 2c and d). This confirmed the lack of continuity with the phalangeal medulla, a characteristic feature of BPOP that differentiates it from an osteochondroma, which maintains medullary continuity. Histology confirmed the diagnosis.

\section{References}

1. Nora FE, Dahlin DC, Beabout JW. Bizarre parosteal osteochondromatous proliferations of the hands and feet. Am J Surg Pathol. 1983;7:245-50.
2. Kumar A, Khan SA, Sampath Kumar V, et al. Bizarre parosteal osteochondromatous proliferation (Nora's lesion) of phalanx in a child. BMJ Case Rep. 2014; https://doi.org/10.1136/bcr-2013-201714

3. Hussain MM, Arif KS. Bizarre parosteal osteochondromatous proliferation causing angular deformities: a case report. J Orthop Case Rep. 2015;5:45-7.

4. Stahl S, Schapira D, Nahir AM. Turret exostosis of the phalanges presenting as limited motion of the finger. Eur J Plastic Surg. 2000;23:82.

5. Touraine S, Wybier M, Sibileau E, Genah I, Petrover D, Parlier-Cuau $\mathrm{C}$, et al. Non-traumatic calcifications/ossifications of the bone surface and soft tissues of the wrist, hand and fingers: a diagnostic approach. Diagn Interv Imaging. 2014;95:1035-44.

6. Gruber G, Giessauf C, Leithner A, et al. Bizarre parosteal osteochondromatous proliferation (Nora lesion): a report of 3 cases and a review of the literature. Can J Surg. 2008;51:486-9.

7. Berber O, Dawson-Bowling S, Jalgaonkar A, et al. Bizarre parosteal osteochondromatous proliferation of bone: clinical management of a series of 22 cases. J Bone Joint Surg (Br). 2011;93:1118-21. 